\title{
Construção, negociação e desconstrução de identidades:

\author{
do movimento homossexual ao LGBT ${ }^{*}$
}

\section{Glaucia da Silva Destro de Oliveira**}

$\mathrm{Na}$ trilha do arco-íris (2009) desenha os contornos e as nuances da trajetória do movimento homossexual no Brasil. É com o intuito de traçar esse percurso que os antropólogos Júlio Simões e Regina Facchini apresentam seu mais recente livro sobre as transformações do movimento homossexual ao LGBT. Nele, o leitor deflagra o movimento de construção, negociação $e$ desconstrução de identidades no universo homossexual.

Seu ponto inicial é a década de 1950, quando não existia movimento social organizado ainda no contexto brasileiro. Esse momento é marcado pelas iniciativas relacionadas à sociabilidade, como festas, assembléias e reuniões. A organização política acontece na década de 1970 com a formação de grupos e jornais caseiros.

Depois de uma introdução, indicando questões importantes para o debate de gênero e de movimentos sociais na contemporaneidade, os autores apresentam os diferentes momentos do movimento homossexual - ou as ondas, como eles mesmos chamam - para, então, detalharem com precisão cada um desses.

\footnotetext{
* Resenha de SIMÕES, Júlio Assis; FACCHINI, Regina. Na trilha do arco-íris: do movimento homossexual ao LGBT. São Paulo, Editora Fundação Perseu Abramo, 2009, 196p. Recebida para publicação em maio de 2010, aceita em junho de 2010.

** Doutoranda pelo Programa de Pós-Graduação em Ciências Sociais - linha Cultura e Poder, Instituto de Filosofia e Ciências Humanas, Unicamp. gdestro@gmail.com
}

cadernos pagu (34), janeiro-junho de 2010:373-381. 
Construção, negociação e desconstrução de identidades

A primeira onda é marcada pelo final do regime militar, em 1978. A seguinte aconteceu durante o processo de democratização dos anos 1980 e a mobilização em torno da Assembléia Constituinte, que coincide com a eclosão do HIV-Aids. Esses adventos transfiguram as iniciativas realizadas até então, atribuindo ao movimento novas características, novos objetivos, novas estratégias de ação e, ainda, estão inseridos em novos contextos. A terceira deu-se a partir dos anos 1990 quando o movimento encontra-se em parceria com o Estado e com o mercado segmentado.

Nesse sentido, o livro apresenta iniciativas, desdobramentos e projetos dos movimentos homossexuais no Brasil desde a década de 1970 até os dias de hoje. As organizações políticas e publicações referentes à temática estão no primeiro plano da descrição, de forma a traçar a trajetória - que não é linear e nem crescente - da mobilização política desse movimento. É interessante atentar para a forma como os autores desenham cada momento desse percurso com detalhes e extenso material (fotos, reprodução de publicações e narrativas), de modo a inserir o leitor nas esferas sociais descritas, construindo certo sentimento de aproximação com os contextos.

A linguagem do texto é simples e direcionada ao público leigo na temática homossexual, bem como no debate antropológico. Ao traçar o enredo dessas mobilizações políticas, os autores promovem, de forma sutil e elegante, a discussão contemporânea acerca de conceitos como o de cultura, de identidade e de política, tão duros e caros à disciplina. Um leitor iniciante pode não se atentar ao debate teórico contemporâneo apresentado, mas, certamente, com a leitura do texto terá propriedade e argumentos para compreender que as identidades não são tomadas como determinações fixas e inatas. Ao contrário, a obra explicita exatamente a dinâmica desses movimentos políticos e de categorias que eles produzem e acionam, a partir da ação de diversos agentes, de contextos específicos e das organizações sociais em que estão inseridos. Dessa forma, o livro, 
além de promover um entendimento sobre o movimento homossexual no Brasil $e$ informar o leitor sobre momentos da discussão antropológica contemporânea, pode também contribuir para o debate nas Ciências Sociais interessado na construção $e$ desconstrução da noção de identidade. Na trilha do arco-íris é uma demonstração desses rearranjos e negociações entre campos de disputa que oscilam entre o tom contestatório e o reforço de uma imagem pública respeitável do homossexual.

Uma tensão presente na discussão teórica atual sobre movimentos sociais consiste na insistência de seus agentes em essencializar categorias, a fim de se fortalecer politicamente $e$ vocalizar demandas; no entanto, é notável a fluidez identitária.

Nesse sentido, o movimento homossexual da segunda metade dos anos 1980 tende a afastar-se de identidades consideradas até então desviantes, como é o caso de travestis ${ }^{1}$. Butler (2003a, b) já nos atentara de que todo modo classificatório é excludente. Stuart Hall (2003) afirma que a diferença dá-se através da diversidade, que pode ser traduzida através da tendência à hierarquização dos termos e/ou, ainda, promover a pluralidade. Por isso, esse autor afirma que a diferença que importa é aquela plural, heterogênea e que, ao contrário de aprisionar, liberta-se. Nesse sentido, prima-se pela valorização das diferenças e das particularidades e se ressaltam as políticas culturais da diferença. Hall sugere adoção de "essencialismo estratégico" como saída para se deslocar posições de poder em momentos propícios para a mobilização política. A cultura, nesse sentido, é tida como espaço do contraditório, marcado por tensões e disputas constantes. Pois a identidade produzida no discurso não é fixa, mas está em constante processo.

Os termos centrais no texto são homossexualidade, identidade e política, para, então, tratar de identidade

1 As travestis, segundo os autores, estão em posição mais vulnerável aos crimes violentos de execução sumária por estarem expostas à pobreza, à identidade de gênero percebida como desqualificada, à proximidade estabelecida com a prostituição, o delito e o comércio de drogas ilícitas. 
Construção, negociação e desconstrução de identidades

homossexual. A idéia da identidade acionada - tem o sentido de fluidez e hibridez e também é situacional, relacional $e$ contingencial (Brah, 2006; Butler, 2003a,b; Hall, 2003) - concentra a discussão promovida ao mostrar como categorias são criadas, recriadas e transformadas ao longo dos anos, a partir de expectativas, interesses e contextos específicos.

Nas primeiras décadas, a mobilização política foi pautada pelos sujeitos de forma a construir uma identidade homossexual, a partir de microestruturas. O objetivo era apreender as violências $e$ discriminações específicas nas trajetórias individuais, como era o caso das reuniões "de identificação" do grupo SOMOS, que giravam em torno dos depoimentos. Esse grupo foi fundado em São Paulo em 1978, inspirado no movimento argentino Nuestro Mundo da Frente de Liberación Homossexual (FLH). Os autores tomam o SOMOS como a primeira proposta de politização da questão da homossexualidade ${ }^{2}$ no Brasil, de caráter contestatório $e$ anti-autoritário. Ele foi, inicialmente, formado por um pequeno coletivo de homens exclusivamente e, aos poucos, foi crescendo $e$ contou também com a participação de mulheres. A ideia do grupo era discutir sexualidade a partir das vivências de seus integrantes, na tentativa de se construir uma identidade coletiva. Como lembra-nos Foucault (2005), não existe sujeito pré-discursivo. Nessa lógica, os conceitos são criados a partir de enunciações. E, como será possível visualizar, a descontinuidade é uma forte marca do debate posto ( $e$ das identidades em questão), já que, nesse arcabouço teórico, os significados disputam, constantemente, o estatuto da verdade.

\footnotetext{
2 No contexto de agrupamentos em que a temática da homossexualidade estava em pauta antes deste movimento político, são as associações que desde a década de 1950, aproximadamente, promoviam a sociabilidade entre homens principalmente, com a realização de concursos de miss, show de travestis $e$ desfiles de fantasia, no tom de paródia e diversão. No período de 1963 a 1969 , no Rio de Janeiro, havia o jornal artesanal chamado de O Snob também com pouco tom militante. Essas eram umas das formas de vivências individuais $e$ coletivas de homoerotismo num contexto de clandestinidade.
} 
Outro agente importante no cenário da primeira onda foi o jornal Lampião lançado em 1978. De formato tablóide e estilo irreverente e anárquico, utilizava linguagem popular do meio homossexual. O uso de termos como "bicha", "boneca", "veado" tinha o intuito de esvaziar seu sentido pejorativo, o que também representava um modo de pertencimento, prática também comum no grupo SOMOS.

A substituição de termos duais como "bofes" (referente a adjetivos como "ativos" $e$ "masculinos") e "bichas" (tratando-se de "passivas" e "femininas") por "entendidos" e "gays" reorganiza a relação entre aqueles que compõem a cena homossexual, diluindo a hierarquização presente no primeiro modelo, re-configurando as relações e identidades no universo homossexual, segundo os autores, e restabelece posições de igualdades entre esses diferentes atores.

$\mathrm{O}$ projeto político do movimento era um ponto de discordância. Se alguns privilegiavam como pauta de luta a transformação social, tendo como enfoque a oposição frente à ditadura militar, outros reivindicavam as causas específicas das minorias, como a de mulheres, a de negros e a de homossexuais. Essas duas frentes não esbarraram ou coincidiram com as questões presentes no momento posterior.

A análise do processo histórico de construção das identidades homossexuais, da forma como elas foram traçadas, organizadas e re-atualizadas, revela a pluralidade de possibilidades que constituiu esse campo. Nesse sentido, sua configuração atual, mais do que o resultado de um enredo linear, se apresenta como conseqüência de articulações de diferentes movimentos sociais, atores políticos e organizações da sociedade brasileira contemporânea.

Nesse caso, vale atentar para as transformações do movimento de cada onda. Pois, se elas estabeleceram entre si uma relação de continuidade que envolve o reconhecimento da ação anterior dos outros grupos, por outro lado, não se encontra um desenvolvimento linear que una os diferentes momentos em 
Construção, negociação e desconstrução de identidades

uma contigüidade ou em um todo seqüencial. Ao contrário, as expectativas, as estratégias $e$ as concepções são muito diferentes em cada período do movimento. E essas mudanças não cabem necessariamente aos grupos. Os contextos sociais e históricos também atuam, de modo a desmobilizar certa estratégia ou exigir certo enquadramento da mobilização e, portanto, possibilitam que o trajeto do movimento mude de sentido.

Nas décadas seguintes, portanto, os tipos de estratégia dos movimentos da primeira onda, de compartilhar experiências ou de uso de termos para fincar noções acerca da homossexualidade, deixaram de ser o foco da atuação, em favor da articulação do movimento com outras esferas da sociedade. Os grupos acionavam, então, modos de se diferenciar das estratégias anteriores a eles, procurando marcar novos modelos de atuação política. Para o Triângulo Rosa - movimento que fez parte da segunda onda -, por exemplo, a dinâmica de reuniões e atuação do grupo SOMOS tinha o caráter de "terapia" caracterizada pela auto-ajuda, atribuindo-lhe certo tom a-político. Sua ação está voltada para a instância institucional e sua atuação reside junto ao Legislativo e ao Judiciário. Nesse sentido, o caráter mais individual de uma identidade homossexual pouco entrava em pauta; seu projeto era delinear uma imagem pública de homossexual respeitável.

Os contextos e adventos sofridos na sociedade brasileira em cada momento histórico articulados com as demandas, os interesses $e$ as expectativas dos grupos políticos configuram $e$ resultam no percurso do movimento e da imagem homossexual no Brasil. Em outras palavras, o deslocamento a que tais dinâmicas remetem e que ora configuram o movimento contestatório, ora o movimento institucionalizado, permite apreender a riqueza etnográfica que envolve a história da politização da homossexualidade no Brasil e, ainda, visualizar discussões de fundo mais teórico, como já mencionado neste trabalho. 
A democratização da sociedade brasileira implicou efeitos $e$ transformações que resultaram na conclusão de uma onda e o início de outra, sob nova configuração. Esse novo período é marcado pela fragilização da imprensa alternativa, com a abertura do mercado e da grande mídia. A expansão das possibilidades de consumo voltada ao público homossexual esvaziou a empreitada de financiar um jornal de teor fortemente político, cuja realização já era considera difícil. Em meio a discussões e diferentes posicionamentos a respeito de sua viabilização do ponto de vista comercial, o jornal Lampião fechou em 1981. O grupo SOMOS foi dissolvido anos depois.

Vale lembrar que a mídia alternativa era importante para a manutenção dos grupos organizados, na medida em que construía uma esfera de comunicação entre as atividades dos diferentes grupos sendo um veículo de divulgação de iniciativas $e$ ações. Dessa forma, as publicações caseiras provocavam um sentimento de pertencimento a um movimento que extrapolava suas ações locais. No jornal pequeno, em suas diversas seções - como o espaço para os leitores - também se produziam discursos, semelhanças e diferenças. $O$ fim das publicações trouxe um impacto no que concerne à visibilidade desses grupos locais atuando para a sua desmobilização política, devido às dificuldades de divulgação ou propagação de suas iniciativas e ações. Os jornais, portanto, funcionavam com elemento articulador do movimento, tendo um papel fundamental naquele contexto.

O mesmo período - meados da década de 1980 - também foi marcado pela eclosão do HIV/AIDS, advento que colocou a homossexualidade e a sexualidade como foco de atenção do debate público de modo até então não experimentado, com forte presença do poder médico, apoiado pela mídia. Por outro lado, com o intuito de se afastar da relação entre homossexualidade $e$ doença, movimentos - como Triângulo Rosa - primaram pelo reconhecimento e diálogo com as instâncias estatais e associações profissionais. A ideia era promover uma imagem respeitável do 
Construção, negociação e desconstrução de identidades

homossexual, com o objetivo de se alcançar o reconhecimento da sociedade e do Estado. ${ }^{3}$

Atualmente, o movimento homossexual encontra-se sob nova estrutura social: forte presença da mídia e de outros movimentos sociais, diálogo com redes internacionais de defesa de direitos humanos, atuação junto às agências estatais, respostas diante das organizações religiosas, manifestações de dia do Orgulho Gay. Seu formato institucional é regido pelo modelo das organizações não-governamentais (ONGs) em que certa infraestrutura e organização são exigidas pela necessidade do financiamento e institucionalização.

Os autores apresentam a identidade homossexual atual, denominada LGBT, sobre bases mais porosas, cujas fronteiras estão entre a diversão, o comércio e a militância. A mobilização em torno do combate à homofobia tem estado no centro da busca por conquistas no campo dos direitos e da política, num movimento homossexual tão multifacetado, aglutinando demandas e reivindicações.

O mercado GLS e "a expansão dos espaços de sociabilidade homossexual", para usar a terminologia dos autores, apresentam expressões estéticas e estilos de vida vinculados ao movimento LGBT: "orgulho" gay, "visibilidade" e a bandeira de arco-íris. Do lado do movimento, verificam-se também pontos de comunicação com aspectos reconhecidos como do mercado: a presença de trios elétricos de casas noturnas nas Paradas do Orgulho LGBT, para citar apenas um exemplo, atesta essa articulação. Essa manifestação, marcada pela visibilidade política e também de referência de sociabilidade em clima de festividade, apresenta bem o caráter fluido de atuação e a ausência de um espaço marcado

3 Nesse momento, a tensão entre escolha individual e determinação biológica, psicológica ou social do homossexual foi solucionada pela substituição do uso de "opção sexual" ou "condição homossexual" por "orientação sexual". Diminuída a tensão entre uma essência ou uma opção, a categoria "orientação sexual" se torna, a partir de então, base a partir da qual se leva a discussão acerca de direitos de homossexuais ao espaço público. 
Glaucia da Silva Destro de Oliveira

pela ação de apenas um segmento social voltado à homossexualidade atualmente.

A obra de Júlio Simões e Regina Facchini desenha diversos desdobramentos do movimento LGBT, enfatizando porosidade entre o Estado e a sociedade civil. Para concluir, trata-se de dinâmicas sociais específicas que o movimento deve incorporar, mas, por outro lado, diz respeito a interesses e necessidades determinadas que, de certa forma, a configuração histórico-social responde e absorve de diferentes formas. É a junção e a articulação desses diversos atores, sem a determinação de algum agente ou esferas, que proporcionaram as configurações dos movimentos homossexuais em período tão curto no Brasil.

\section{Referências bibliográficas}

BRAH, Avtar. Diferença, diversidade, diferenciação. Cadernos Pagu (26), Campinas-SP, Núcleo de Estudos de Gênero-Pagu/Unicamp, 2006, pp.329-376.

ButLER, Judith. Problemas de Gênero: Feminismo e subversão da identidade. Rio de Janeiro, Civilização Brasileira, 2003a.

O parentesco é sempre tido como heterossexual? Cadernos Pagu (21), Campinas-SP, Núcleo de Estudos de Gênero Pagu/Unicamp, 2003b, pp.219-260.

FoucAult, Michel. História da Sexualidade, vol.01. Rio de Janeiro, Graal, 2005.

HALL, Stuart. Que negro é esse na cultura negra In: HALL, S. Da Diáspora: identidades e mediações culturais. Belo Horizonte, UFMG, 2003, pp.317-330. 